\title{
Somatic and germ cell cytogenetic studies and AZF microdeletion screening in infertile men
}

\author{
Rita C.V. Carrara ${ }^{1}$, Rui Yamasaki ${ }^{2}$, Luis F. Mazucatto ${ }^{1}$, Maria A. Llorach Veludo ${ }^{3}$, \\ Edi L. Sartorato ${ }^{4}$ and João M. Pina-Neto ${ }^{1}$ \\ ${ }^{1}$ Universidade de São Paulo, Faculdade de Medicina de Ribeirão Preto, Departamento de Genética, \\ Ribeirão Preto, SP, Brazil. \\ ${ }^{2}$ Universidade de São Paulo, Departamento de Cirurgia do Hospital das Clínicas \\ da Faculdade de Medicina de Ribeirão Preto, Ribeirão Preto, SP, Brazil. \\ ${ }^{3}$ Universidade de São Paulo, Departamento de Patologia do Hospital das Clínicas \\ da Faculdade de Medicina de Ribeirão Preto, Ribeirão Preto, SP, Brazil. \\ ${ }^{4}$ Universidade de Campinas, Centro de Biologia Molecular e Engenharia Genética, Campinas, SP, Brazil.
}

\begin{abstract}
Clinical and cytogenetic studies were performed in 65 infertile individuals, and 56 of them were also screened for microdeletions in Yq11 (AZF region). Relevant environmental etiological factors were identified in 10 cases (15.4\%). Sertoli-cell-only syndrome was diagnosed in six patients $(9,2 \%)$. Karyotype abnormalities were detected in six individuals, and five other patients presented desynapsis of bivalents in meiosis. Three out of the 56 patients studied were carriers of microdeletions in the AZF region, one of them also presenting a chromosomal mosaicism for an extra i(22p).
\end{abstract}

Key words: male infertility, cytogenetics, microdeletions, AZF, meiotic anomalies.

Received: May 21, 2002; Accepted: October 7, 2004.

\section{Introduction}

The chromosome abnormalities associated with infertility are of two types: karyotype alterations affecting cells of both somatic and germ cell lines, and meiotic abnormalities. Both types can produce infertility, either by spermatogenesis arrest or formation of chromosomally unbalanced gametes, leading to spontaneous abortions and/or offspring with mental deficiency and malformations (Navarro et al. 1987).

The frequency of karyotype alterations in infertile men is around $7 \%$, and it inversely correlates with sperm count: $13.7 \%$ of the azoospermic men and $4.6 \%$ of the oligozoospermic men $\left(<20 \times 10^{6}\right.$ sperm $\left./ \mathrm{mL}\right)$ have abnormal karyotypes (De Braekeleer and Dao, 1991). Sexchromosome abnormalities (mainly the 47,XXY karyotype) predominate in azoospermic men, while reciprocal and Robertsonian translocations involving autosomes are more frequent in oligozoospermic men (Van Assche et al. 1996). Meiotic chromosome abnormalities are found in

Send correspondence to Rita de Cássia Viu Carrara. Universidade de São Paulo, Faculdade de Medicina de Ribeirão Preto, Departamento de Genética, Av. Bandeirantes 3900, 14049-900 Ribeirão Preto, SP, Brazil. E-mail: carrara@ pegasus.fmrp.usp.br. approximately $6 \%$ of the infertile patients (Egozcue et al. 1983; De Braekeleer and Dao, 1991), and this frequency increases to $17.5 \%$ in patients with severe oligozoospermia ( $\left.\leq 1 \times 10^{6} \mathrm{sperm} / \mathrm{mL}\right)$ (Vendrell et al. 1999).

Meiotic abnormalities not associated with chromosome aberrations include synaptic alterations and meiotic suppression (Navarro et al. 1987). Gene mutations may alter the pairing of homologous chromosomes. The synaptic abnormalities are of two types, asynapsis or desynapsis, and may lead to the formation of univalents, thus causing altered segregation of chromosomes with the formation of chromosomally unbalanced gametes, or spermatogenesis arrest (Vidal et al. 1982; Navarro et al. 1986; Bascon-Slack et al. 1997). Asynapsis results from disturbances in pairing during prophase I and is characterized by lack of the sex vesicle. In all reported cases of asynapsis, there was a meiotic block in spermatocyte I. On the other hand, desynapsis is associated with apparently normal bivalent pairing and sex vesicle formation, followed by premature separation of paired chromosomes during diplotene stage. (Templado et $a l ., 1976)$. Desynapsis appears to be the most frequent synaptic anomaly among infertile men, and is characterised by the low frequency of chiasmata in metaphase I, producing 
anomalous figures of bivalents (Egozcue et al.,1983). The desynaptic chromosomes are long and thin, with only one or no chiasmata, and a variable number of univalents is observed in metaphase I (Templado et al., 1976). This anomaly may affect all the spermatocyte bivalents (complete desynapsis) or only some of those (individual desynapsis), occurring in all or just in some cells (total or partial desynapse, respectively), and sometimes is associated to chromosome fragmentation (Templado et al., 1981).

Male infertility may still be caused by microdeletions of the $\mathrm{Y}$ chromosome in Yq11.23, where the spermatogenesis controlling genes, referred to as the azoospermia factors (AZF), are mapped (Tiepollo and Zuffardi, 1976; Chandley, 1979). Microdeletions in the Yq11 have been reported in $10 \%$ to $15 \%$ of infertile men with azoospermia or idiopathic severe oligozoospermia (Ferlin et al. 1999). Analyses of these deletions have shown that at least three loci (AZFa, AZFb, and AZFc) are required for normal spermatogenesis, and several genes have been mapped as candidates for AZF at these loci (Vogt et al. 1996).

In this study we performed clinical, and somatic and germ cell cytogenetic analyses in a sample of 65 men with non-obstructive infertility, as well as screened the AZF region for microdeletions in 56 of these cases in order to determine the frequency of these factors as the cause of their spermatogenesis disorders.

\section{Materials and Methods}

\section{Patients}

Sixty-five infertile men with testicular abnormalities of unknown etiology were ascertained at the Outpatient Clinic for Male Infertility of the University Hospital, School of Medicine of Ribeirão Preto, University of São Paulo (HCFMRP-USP). Patients were clinically evaluated by anamnesis, general and specific physical examination and complementary tests (sperm count, hormonal evaluation, histopathological studies by testicular biopsy, seminal vesiculography and ultrasonography). The sample consisted of 27 patients with azoospermia, 19 cases of severe oligozoospermia ( $\leq 1 \times 10^{6}$ sperm $/ \mathrm{mL}$ ), 18 cases of oligozoospermia $\left(1-20 \times 10^{6} \mathrm{sperm} / \mathrm{mL}\right)$ and one patient with a normal sperm count $\left(>20 \times 10^{6} \mathrm{sperm} / \mathrm{mL}\right)$, but presenting with motility alteration (asthenozoospermia). Patients with post-testicular infertility, such as unilateral or bilateral congenital agenesis of the vas deferens, were not included in this study. The control sample for the cytogenetic studies on germ cells was obtained by testicular biopsy from an individual who was about to undergo a vasectomy and had recently proven fertility (a child less than two years before the biopsy was performed). All samples were collected under written consent from the subjects, in accordance with the ethical standards of the committee on human experimentation of the University Hospital (HCFMRP USP).

\section{Cytogenetic analysis}

The somatic karyotype of the 65 patients was studied in cultured peripheral blood lymphocytes. A minimum of 100 metaphases were analyzed per patient, allowing the detection of chromosome mosaics including a minor cell line with a frequency equal or superior to $3 \%$ at the confidence limit of 0.90 or $5 \%$ at the 0.99 confidence limit (Hook, 1977).

The cytogenetic study of germ cells from testicular biopsies was carried out in all 65 patients, following the technique described by Evans et al. (1964). Chromosomal analysis was performed in those patients who presented meiotic activity in prophase I (PI), metaphase I (MI), and metaphase II (MII). In some cases, spermatogonial metaphases (SPM) were also analyzed, depending on the quality of the preparations. The presence of the sex vesicle (SV) was recorded in the pachytene stage, as an indication that asynapsis had not occurred. For evaluation of the metaphase I/metaphase II ratio (MII/MI), all MIs and MIIs observed were recorded, and the best ones were photographed and analyzed. In MI, the number of bivalents, univalents and multivalents, and the number of chiasmata per cell and per chromosome were counted, in order to verify the presence of complete and individual desynapsis. To detect aneuploidy and polyploidy, the number of chromosomes per cell was determined in good quality MII.

\section{Yq11 microdeletions (AZF region)}

Fifty-six of the 65 clinically and cytogenetically studied patients were analyzed for the presence of microdeletions in the AZF region (Yq11). DNA samples from nine patients were not available. Genomic DNA was extracted from peripheral blood cells and amplified by multiplex PCR using 28 Y chromosome-specific STS (sequence-tagged sites), according to Henegariu et al. (1994). Reaction products were separated on $3 \%$ agarose gels (Metaphor, FMC Bioproducts) and stained with ethidium bromide. The deletion of one or more PCR fragments was confirmed in single-primer pair PCR under the same experimental conditions. This analysis was performed at least three times for each microdeletion.

\section{Results}

The clinical evaluation of the 65 patients disclosed relevant environmental etiological factors in 10 of them (15.4\%). Medical history of leprosy, post-puberty parotiditis, orchitis, varicoleces, testicular traumas and chemotherapy were considered as relevant, since these occurrences correlated with the histopathological and/or other clinical findings. Six patients with azoospermia (9.2\%) presented germ cell aplasia or Sertoli-cell-only syndrome (SCO type I - MIM 305700, OMIM), diagnosed in the 
Table 1 - Karyotype abnormalities detected in 65 infertile men.

\begin{tabular}{lcc}
\hline Cases & Karyotype & $\mathrm{N}$ sperm $/ \mathrm{mL}$ \\
\hline $\mathrm{I}-9$ & $47, \mathrm{XY},+\mathrm{i}(22 \mathrm{p})(10) / 46, \mathrm{XY}(90)$ & 0 \\
$\mathrm{I}-26$ & $47, \mathrm{XXY}(3) / 46, \mathrm{XY}(97)$ & 0 \\
$\mathrm{I}-27$ & $45, \mathrm{XY}, \mathrm{rob}(13 \mathrm{q} ; 14 \mathrm{q})$ & $1,2 \times 10^{6}$ \\
$\mathrm{I}-52$ & $47, \mathrm{XXY}(48) / 46, \mathrm{XY}(52)$ & 0 \\
$\mathrm{I}-54$ & $47, \mathrm{XXY}$ & 0 \\
$\mathrm{I}-58$ & $47, \mathrm{XXY}$ & 0 \\
\hline
\end{tabular}

histopathological examination. Six patients $(9.2 \%)$ had karyotype abnormalities (Table 1). A 13/14 Robertsonian translocation [45,XY,rob(13q;14q)] was detected among the 18 oligozoospermic individuals, and the other five chromosome abnormalities were found in the group of 27 azoospermic patients. The most frequent chromosome abnormality was Klinefelter syndrome, in four patients $(6.2 \%$ - 4/65): two individuals with the karyotype 47,XXY, and two mosaics [47,XXY(3)/46,XY(97) and 47,XXY(48)/ 46, $\mathrm{XY}(52)]$. One mosaic patient carried an extra isochromosome 22p [47,XY,+i(22p)(10)/46,XY(90)] identified as such by FISH with probes annealing to chromosomes 14 and 22 (FISH analysis was kindly performed in Dr. A. Shinzel's laboratory, Institute of Medical Genetics, Schwerzenbah, Switzerland).

In the chromosome analysis of germ cells, about $17 \%$ (11/65) of the patients showed cells entering meiosis I, progressing to meiosis II, beyond the MII phase (MII/ $\mathrm{MI} \geq 0.5)$, and were considered to have complete meiotic activity (Group A). Approximately 55.3\% (36/65) of the patients showed spermatogenesis suppression of various degrees, in different stages (Group B), while in 27.7\% $(18 / 65)$ no cells in meiotic division were detected (Group C). Table 2 shows the cell distribution according to the stages of spermatogonial metaphase (SPM), diakinesis/ metaphase I (MI) and metaphase II (MII), the average chiasmata number (xma), and the metaphase II/metaphase I ratio $(\mathrm{MII} / \mathrm{MI})$ in infertile men with meiotic activity (Groups A and B) and in the control.

Infertile individuals in Group A, considered as having complete meiotic activity, showed reduction in the number

Table 2 - Germ cell cytogenetic analysis in the 47 infertile men with meiotic activity and in a normal control.

\begin{tabular}{lccccc}
\hline Samples & SPM & MI & MII & $\mathrm{R}_{\mathrm{a}}$ & $\mathrm{MII} / \mathrm{MI}$ \\
\hline $\begin{array}{l}\text { Group A* } \\
\mathrm{N}=11\end{array}$ & $0-7$ & $1-43$ & $1-28$ & $43.8-62$ & $0.53-1.0$ \\
$\begin{array}{l}\text { Group B** } \\
\mathrm{N}=36\end{array}$ & $0-6$ & $0-42$ & $0-35$ & $41.0-53.5$ & $0-4.5$ \\
\hline Control & 26 & 188 & 153 & 47.8 & 0.8 \\
\hline
\end{tabular}

*Complete meiotic activity. **Meiotic supression.

SPM, spermatogonial metaphase; MI, metaphase I; MII, metaphase II. $\mathrm{R}_{\mathrm{a}}$ : Range of average chiasmata number. of cells undergoing division, compared to the control subject, pointing to testicular factors directly or indirectly associated to their sterility. In the control subject, the MII/MI ratio of $0.8(153 / 188)$ showed that most cells entering meiosis I progressed to meiosis II.

In the control sample, a total of 367 metaphases were found, $304(83 \%)$ technically adequate for analysis. The frequency of metaphases that could be analyzed was smaller in patients of group A (complete meiotic activity; $153 / 324=47.2 \%$ ), and Group B (meiotic suppression; $574 / 1181=55.5 \%$ ). Most analyses were carried out in MI, since SPM and MII generally showed a degenerated aspect. SPMs of good quality were evaluated for the number of chromosomes per cell, and those presenting 46 chromosomes were considered as $46, \mathrm{XY}$, since it is frequently impossible to classify these chromosomes due to their poor morphology. One polyploid spermatogonial cell was observed in a group A patient.

In all 47 subjects with meiotic activity, approximately 100 cells in pachytene were examined and all showed normal pairing and SV. The possibility of asynapsis was then discarded.

Five patients (5/65; I-1, I-3, I-36, I-40, and I-41) presented with synaptic abnormalities of the desynapsis type, including univalents and/or large bivalents with only one terminal chiasma (Table 3 ). In all five patients a variable number of cells showed desynapsis (partial desynapsis) and not all bivalents were affected (individual desynapsis; Figure 1b), but for one single cell that showed complete
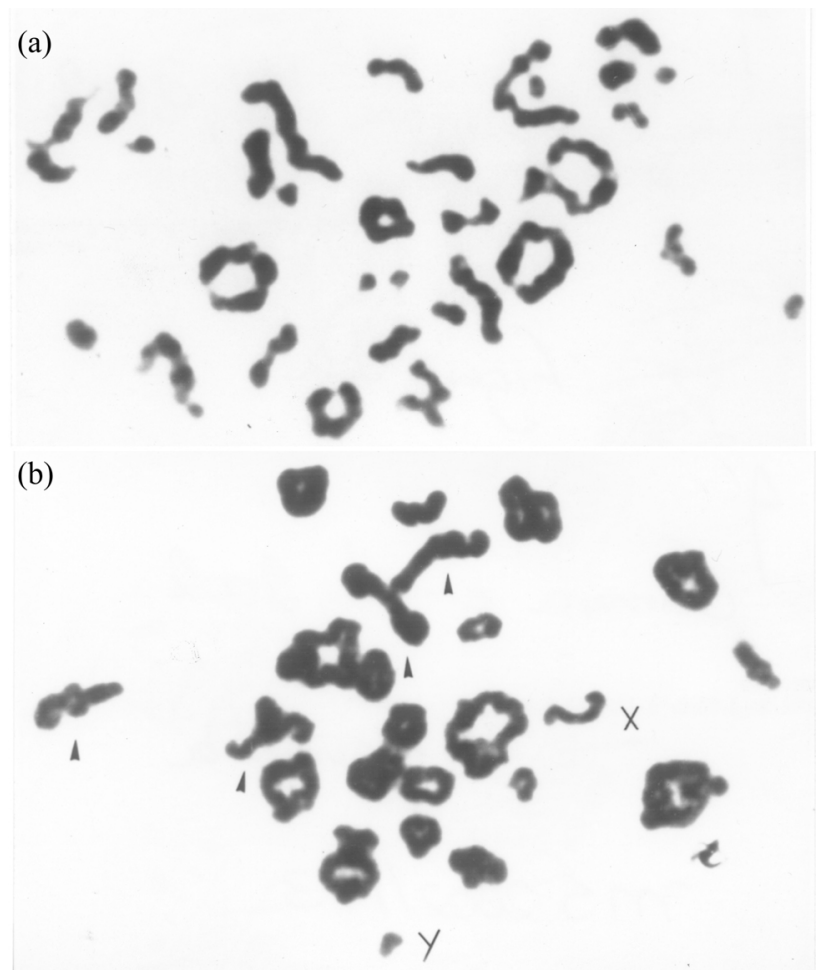

Figure 1 - (a) Metaphase with complete desynapsis; (b) Metaphase with individual desynapsis of autosomal (arrows) and XY bivalents. 
Table 3 - Metaphase I (MI) analysis in five infertile men presenting with meiotic desynapsis.

\begin{tabular}{|c|c|c|c|c|c|c|c|}
\hline \multirow{3}{*}{ Case } & \multirow{3}{*}{$\begin{array}{l}\text { MI analyzed } \\
\text { / MI found }\end{array}$} & \multicolumn{6}{|c|}{ Number of metaphases I } \\
\hline & & \multicolumn{3}{|c|}{ Partial desynapsis } & \multirow{2}{*}{$\begin{array}{l}\text { XY bivalent } \\
\text { dissociation }\end{array}$} & \multirow{2}{*}{$\begin{array}{c}\text { Autosomal } \\
\text { univalents }\end{array}$} & \multirow{2}{*}{$\begin{array}{l}\text { Decreased number of } \\
\text { interstitial chiasmata }\end{array}$} \\
\hline & & Complete & Individual & Total & & & \\
\hline $\mathrm{I}-1$ & $10 / 19$ & 0 & 2 & $2^{*}$ & 0 & 0 & 2 \\
\hline $\mathrm{I}-3$ & $16 / 44$ & 0 & 1 & 1 & 1 & 0 & 1 \\
\hline $\mathrm{I}-36$ & $48 / 50$ & $1^{* *}$ & 19 & 20 & 13 & 2 & 20 \\
\hline $\mathrm{I}-40$ & $23 / 30$ & 0 & 1 & 1 & 1 & $1 * * *$ & 1 \\
\hline I-41 & $32 / 69$ & 0 & 2 & 2 & 1 & $1 * * *$ & 1 \\
\hline
\end{tabular}

*MI with two large bivalents showing only one terminal chiasma in one chromosome arm.

**MI shown in Figure 1a.

***MI with one autosomal bivalent dissociated in two univalents

desynapsis (patient I-36; Figure 1a). Patients I-1, I-3 and I-36 had an average number of chiasmata $(43.7 \pm 8.4$, $41.3 \pm 4.7$ and $40.8 \pm 4.1$, respectively) lower than that observed in normal fertile individuals (50.0 \pm 6 ) (Templado et al., 1981) and than that observed in the control subject $(47.8 \pm 4.5)$. All the patients with desynapis had normal somatic karyotypes. Patient I-1 reported that his parents were first cousins, and that his maternal grandparents also were cousins (unknown degree). Three of his maternal first cousins once removed were childless. Patient I-36's parents were first cousins and one maternal uncle was reported as having fertility problems.

In patient I-9, with the $47, \mathrm{XY},+\mathrm{i}(22 \mathrm{p})(10) / 46, \mathrm{XY}(90)$ karyotype, an extra small fragment was observed in one out of eight MIs analyzed. His fertile brother did not carry this marker chromosome.

Microdeletions in the AZF region were found in three patients (I-9, I-39 and I-44) out of 56 analyzed (5.3\%), and in all cases they were located in the AZFc region, involving the DAZ (deleted in azoospermia) gene (Figure 2). One of these patients (I-9) was the mosaic carrier of the extra i(22p). Patient I-44's father, and patients I-9's and I-39's fertile brothers did not have the microdeletions, thus demonstrating that these were de novo events. Of the nine pa- tients who were not screened for microdeletions, environmental etiological factors were identified in three cases, two patients had meiotic abnormalities and two other patients presented germ cell aplasia. Two patients remained without an etiological diagnosis.

Karyotype abnormalities were generally found in azoospermic individuals, while meiotic pairing abnormalities and AZF microdeletions were distributed among the azoospermic and severely oligospermic individuals $(<1 \mathrm{x}$ $10^{6} \mathrm{sperm} / \mathrm{mL}$ ). One of the patients with desynapsis had a

Table 4 - Distribution of AZF microdeletions, and karyotype and meiotic abnormalities according to sperm counts in infertile men.

\begin{tabular}{lccc}
\hline \multicolumn{4}{c}{ Individuals with } \\
\hline $\begin{array}{l}\text { N Sperm/mL } \\
\left(\times 10^{6}\right)\end{array}$ & $\begin{array}{c}\text { Karyotype } \\
\text { abnormalities }\end{array}$ & $\begin{array}{c}\text { Meiotic } \\
\text { desynapsis }\end{array}$ & $\begin{array}{c}\text { AZF } \\
\text { microdeletions }\end{array}$ \\
\hline 0 & $5 * / 27$ & $1 / 27$ & $2 * / 23$ \\
$\leq 1$ & $1 / 19$ & $3 / 19$ & $1 / 17$ \\
$1-20$ & $0 / 18$ & $0 / 18$ & $0 / 16$ \\
$>20$ & $0 / 18$ & $1 / 18$ & $0 / 0$ \\
\hline Total (\%) & $6 * / 65(9.2 \%)$ & $5 / 65(7.6 \%)$ & $3 * / 56(5.4 \%)$ \\
\hline
\end{tabular}

*One patient carrying a karyotype abnormality $[47, \mathrm{XY},+\mathrm{i}(22 \mathrm{p})(10) / 46$, $\mathrm{XY}(90)]$ and AZF microdeletion.

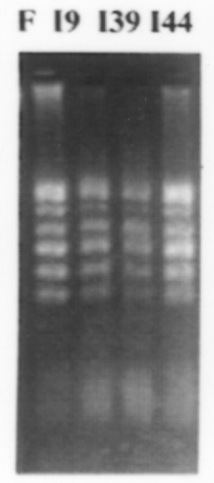

MIX I

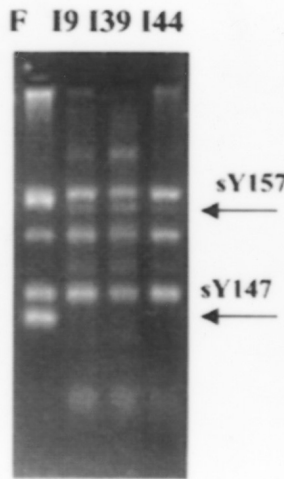

MIX II

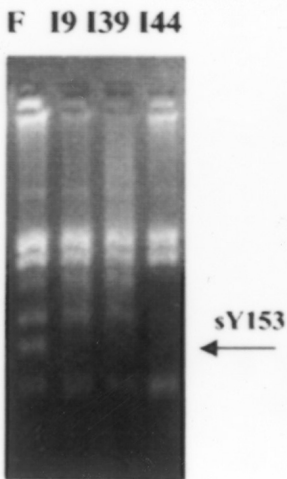

MIX III

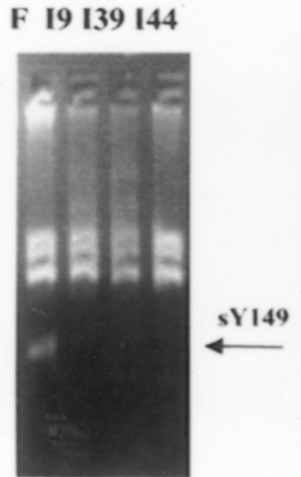

MIX IV

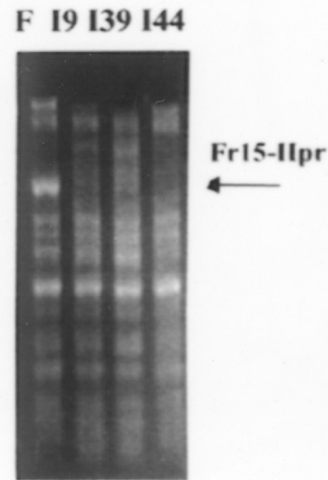

MIX V

Figure 2 - Yq11 microdeletion analysis by multiplex PCR of 28 STSs distributed in five combinations (Mix I to V). F, fertile male; I-9, I-39, and I-44, infertile males, carrying microdeletions. The arrows indicate the STSs amplified only in the control. 
normal sperm count ( $\left.93 \times 10^{6} \mathrm{sperm} / \mathrm{mL}\right)$, but showed abnormal sperm motility (asthenozoospermia) (Table 4).

\section{Discussion}

The methodology used in this study enabled genetic etiology to be determined in about $30 \%$ of the sample of infertile men (Table 5). Among the genetic pathologies, probable monogenic disorders were predominant $(58 \%$ - 11/19), chromosomal abnormalities were detected in $26 \%(5 / 19)$, and AZF microdeletions in 16\% (3/19) of the patients.

In the monogenic disorder group, $45.5 \%(5 / 11)$ patients presented desynapsis, a cytogenetically detectable alteration of genic origin (Lange et al., 1997). The remaining cases $(6 / 11=54.5 \%)$ had Sertoli-cell-only syndrome, which can be caused by several genetic and environmental factors. AZF region microdeletions and androgen receptor $(A R)$ gene mutations are among the known genetic factors (Chandley, 1979; Hiort and Holterhus, 2003). In this study, the affected patients with Sertoli-cell-only syndrome did not present AZF microdeletions, nor $A R$ gene mutations were detected (data not shown). In addition, no environmental factors that could account for the Sertoli-cell-only syndrome were identified. The syndrome was thus considered to be most probably of genic etiology.

Two of the five patients with desynapsis (I-1 and I-36) reported parental consanguinity. This reinforces Ferguson-Smith's hypothesis that this condition is autosomal recessive (personal communication to one of us, JMP-N, Glasgow, Scotland, 1973). However, in view of the family history of recurrent infertility on the maternal side, the hypothesis that this meiotic anomaly is X-linked recessive or male-limited autosomal dominant (Chaganti and German, 1979) is a possibility.

Karyotype alterations were detected in $9.2 \%$ (6/65) of the individuals and about $67 \%(4 / 6)$ were sex chromosome abnormalities, while about 33\% (2/6) corresponded to autosome alterations. The 47,XXY karyotype was the most frequent chromosomal alteration. One case was a mosaic for an extra 22p isochromosome. Extra bisatellited chromosomes (specially chromosome 15) may appear in associa-

Table 5 - Etiological factors diagnosed in the infertile men.

\begin{tabular}{lcc}
\hline Etiological factors & Number of cases & $\%$ \\
\hline Genetic & & \\
Abnormal karyotype & $5 / 65$ & 7.7 \\
Microdeletions & $3 / 56$ & 5.4 \\
A probabable genic disorder & $11 / 65$ & 16.9 \\
$\quad$ Meiotic desynapsis & $5 / 65$ & 7.7 \\
$\quad$ Sertoli-cell-only syndrome & $6 / 65$ & 9.2 \\
Enviromental & $10 / 65$ & 15.4 \\
Idiopathic & $36 * / 65$ & 55.4 \\
\hline
\end{tabular}

*Two patients not tested for AZF microdeletion. tion with male infertility (Martin-Lucas et al. 1986; Gentile et al., 1993; Reddy et al., 2003). Nevertheless, since the patient had a DAZ gene deletion, his spermatogenesis alteration was most probably a primary consequence of this deletion. However, the possibility remains that the extra marker could be a co-factor.

Microdeletions in the AZF region were found in 5.3\% of the 56 cases analyzed, and they were restricted to the AZFc locus, involving the whole DAZ gene. These microdeletions were associated to azoospermia in two cases (I-9 and I-44), and to oligozoospermia in one case (I-39). The histological findings in microdeleted patients varied, and included partial germ cell aplasia, maturation arrest and hypospermatogenesis. This heterogeneity of seminal and histopathological patterns in DAZ gene deletions has been previously described (Vogt et al. 1996; Ferlin et al. 1999; Kraus et al. 1999; Oates et al., 2002).

While most karyotype abnormalities were found among the azoospermic patients, partial desynapsis was not necessarily associated with severe spermatogenesis arrest. Although desynapsis was detected in one azoospermic patient and in three individuals with severe oligozoospermia, it was also observed in one individual with a normal sperm count, showing altered sperm motility.

The frequencies of karyotype abnormalities, meiotic synapsis alterations and AZF deletions among infertile men highlight the importance of genetic testing and counseling when these patients are referred for assisted reproduction.

The number of male infertility cases that remains as idiopathic points to the need of further research on genetic, immunological, and environmental factors that may play a role in the control of spermatogenesis and spermiogenesis.

\section{Acknowledgements}

We thank Dr. Mariluce Riegel and Dr. Albert Schinzel (University of Zurich) for carrying out fluorescent in situ hybridization experiments. We are also very grateful to Dr Cristina Templado, from the Universitat Autonoma Barcelona, for her important contribution in the meiosis studies. This study was supported by Fundação de Amparo à Pesquisa do Estado de São Paulo, FAPESP (grant numbers: 88/0751-2; 88/3089-9; 92/3085-9),

\section{References}

Bascom-Slack CA, Ross LO and Dawsom DS (1997) Chiasmata, crossovers, and meiotic chromosome segregation. Adv Genet 35:253-284.

Cantú JM, Rivas F, Hernández-Jáuregui P, Diaz M, Cortés-Gallegos V, Vaca G; Velázquez A and Ibarra B (1981) Meiotic arrest at first spermatocyte level: A new inherited infertility disorder. Hum Genet 59:380-385.

Chaganti RSK and German J (1979) Human male infertility, probably genetically determined, due to defective meiosis and spermatogenic arrest. Am J Hum Genet 31:634-641. 
Chaganti RSK, Jhanwar SC, Ehrenbard LT, Kourides IA and Williams JJ (1980) Genetically determined asynapsis, spermatogenic degeneration and infertility in man. Am J Hum Genet 32:833-848.

Chandley AC (1979) The chromosomal basis of human infertility. Br Med Bull 35:181-186.

De Braekeleer M and Dao TN (1991) Cytogenetic studies in male infertility: A review. Hum Reprod 6:245-250.

Egozcue J, Templado C, Vidal F, Navarro J, Morer-Fargas F and Marina S (1983) Meiotics studies in a series of 1100 infertile and sterile males. Hum Genet 65:185-188.

Evans EP, Breckon G and Ford CE (1964) An air-drying method for meiotic preparations from mammalian testes. Cytogenetics 3:289-294.

Ferlin A, Moro E, Garolla A and Foresta C (1999) Human male infertility and $\mathrm{Y}$ chromosome deletions: Role of the AZFcandidate genes DAZ, RBM and DFFRY. Hum Reprod 14:1710-1716.

Gentile M, Susca F, Resta N, Stella A, Cascone A and Guanti G (1993) Infertility in carriers of two bisatellited marker chromosomes. Clin Genet 44:71-75.

Henegariu O, Hirschmann P, Kilian K, Kirsch S, Lengauer C, Maiwald R, Mielke K and Vogt P (1994) Rapid screening of the $\mathrm{Y}$ chromosome in idiopathic sterile men, diagnostic for deletions in AZF, a genetic $\mathrm{Y}$ factor expressed during spermatogenesis. Andrologia 26:97-106.

Hiort $\mathrm{O}$ and Holterhus M (2003) Androgen insensitivity and male infertility. Intl J of Androl 26:16-20.

Hook EB (1977) Exclusion of chromosomal mosaicism: Tables of $90 \%, 95 \%$ and $99 \%$ confidence limits and comments on use. Am J Hum Genet 29:94-97.

Kraus C, Quintana-Murci L, Barbaux S, Siffroi JP, Rouba H, Delafontaine D, Souleyreau-Therville N, Arvis G, Plessis G, Bourgeron T, Dadoune JP, Fellous M and McElreavey K (1999) A high frequency of Y chromosome deletions in males with nonidiopathic infertility. Clin Endocrinol Metab 84:3603-3611.

Lange R, Krause W and Engel W (1997) Analyses of meiotic chromosomes in testicular biopses of infertile patients. Hum Reprod 12:2154-2158.

Martín-Lucas MS, Perez-Castilho A and Abrisqueta JA (1986) Infertility associated with two accessory bisatellited chromosomes. Hum Genet 73:133-136.

Moorhead PS, Nowell PC, Mellman WJ, Batipps DM and Hungerford DA (1960) Choromosome preparations of leu- cocytes cultured form human peripheral blood. Exp Cell Res 20:613-616.

Navarro J, Benet J, Garcia M, Vidal F, Freixa L and Templado. C (1987) Citogenética de la infertilidad y la esterilidad. Medicine 100:4223-4230.

Navarro J, Vidal F, Templado C, Benet J, Marina S, Pomerol JM and Egozcue J (1986) Meiotic chromosome studies and sinaptonemal complex analysis by light and electron microscopy in 47 infertile or sterile males. Hum Genet 1:523-527.

Oates RD, Silber S, Brown LG and Page DC (2002) Clinical characterization of 42 oligospermic or azoospermic men with microdeletion of the $\mathrm{AZF}$ c region of the $\mathrm{Y}$ chromosome, and of 18 children conceived via ISCI. Hum Reprod 17:28132824.

Online Mendelian Inheritance in Man (OMIM), http://www.ncbi. nlm.nih.gov/Omim/.

Reddy KS, Wang S, Groh S and Gonatos J (2003) SKY assessment of two karyotypes with 0-6 supernumerary marker/ring chromosomes and review of previously reported cases with two or more markers. Am J Med Genet 118A:156-171.

Templado C, Marina S and Egozcue J (1976) Three cases of low chiasma frequency associated with infertility in man. Andrologia 8:28.

Templado C, Vidal F, Marina S, Pomerol JM and Egozcue J (1981) A new meiotic mutation: Desynapsis of individual bivalents. Hum Genet 59:345-348.

Tiepollo L and Zuffardi O (1976) Localization of factors controlling spermatogenesis in the nonfluorescent portion of the human Y chromosome long arm. Hum Genet 34:119-124.

Van Assche E, Bonduelle M, Tournaye H, Joris H, Verheyen G, Devroey P, Van Steirteghem A and Liebaers I (1996) Cytogenetics of infertile men. Hum Reprod 11(Suppl 4):1-23.

Vendrell JM, Garcia F, Veiga A, Calderón G, Egozcue S, Egoscue $\mathrm{J}$ and Barri PN (1999) Meiotic abnormalities and spermatogenic parameters in severe oligoazoospermia. Hum Reprod 14:375-378.

Vidal F, Templado C, Navarro J, Brusadin S, Marina S and Egozcue J (1982) Meiotic and synaptonemal complex studies in 45 subfertile males. Hum Genet 6:301-304.

Vogt P, Edelmann A, Kirsch S, Kirsch S, Henegariu O, Hirschmann P, Kiesewetter F, Kohn FM, Schill WB, Farah S, Ramos C, Hartmann M, Hartschuh W, Meschede D, Behere HM, Castel A, Nieschlag E, Weidner W, Grone HJ, Jung A, Engel W and Haidl G (1996) Human Y chromosome azoospermia factors (AZF) mapped to different subregions in Yq11. Hum Mol Genet 5:933-943.

Associate Editor: Angela Maria Vianna-Morgante 